\title{
Role of Emotion Regulation as a Buffer against Workplace Stress among Nurses during
} COVID-19

\author{
Fariha Hayat ${ }^{1}$, Neelam Ehsan ${ }^{2}$, Adam Khan ${ }^{3}$, Amna Khan Shahid ${ }^{4}$
}

Abstract

The present study examined the relationship between workplace stress and job satisfaction among nurses along with exploring the moderating role of emotional regulation during the COVID-19 pandemic. A sample of 120 ( $n=60$ male, $n=60$ female) nurses were approached from different public and private hospitals of Islamabad and Rawalpindi, Pakistan. The Workplace Stress Scale, The Minnesota Satisfaction Questionnaire-Short Form, and Emotion Regulation Questionnaire were used to assess workplace stress, job satisfaction, and emotion regulation abilities among nurses. Pearson product-moment correlation and Linear regression analysis were carried out to measure the relationship of workplace stress with job satisfaction and the moderating effect of emotion regulation, respectively. Findings of the study revealed that workplace stress is negatively associated with job satisfaction among nurses. Moreover, moderation analysis indicated that cognitive reappraisal significantly moderated the relationship between workplace stress and job satisfaction. Other key findings of the study indicated that female nurses were higher on workplace stress and used cognitive reappraisal as compared to male nurses who used expressive suppression. Moreover, married nurses were higher on workplace stress as compared to unmarried nurses. Public sector nurses were higher on job satisfaction. The findings of the study suggest that there is a strong need to reduce workplace stress by developing healthy emotion regulation strategies to increase the level of job satisfaction among nurses, especially during this pandemic environment. Keywords: Emotion Regulation, Job Satisfaction, Workplace Stress

Received: 12 December 2021; Revised Received: 27 December 2021; Accepted: 30 December 2021

${ }^{1}$ MS Scholar, Department of Psychology, International Islamic University, Islamabad, Pakistan.

${ }^{2}$ Assistant Professor, Department of Psychology, International Islamic University, Islamabad, Pakistan.

${ }^{3}$ MBBS Scholar, Fazaia Medical College, Air University, Islamabad, Pakistan.

${ }^{4}$ BDS Scholar, Islamic International Dental College, Riphah International University, Rawalpindi, Pakistan.

\section{Corresponding Author Email:}

adamkhan477@gmail.com

\section{Introduction}

Nurses are a crucial part of the health sector and constitute the largest portion of the medical profession. They play a significant role in disease prevention and well-being by providing their amenities in critical and emergency settings in hospitals (Drennan, 2019).Although, there is a worldwide advancement in nursing education, yet unfortunately, nursing remains an undervalued profession in Pakistan and the overall condition of nursing is still a matter of concern (Younas et al., 2019).In the recent surge of the pandemic, the role of health workers especially the nursing community has become even more critical. Although, the literature suggests that researchers have studied various important aspects of nursing practice. And while there is an agreement that

This article is distributed under the terms of the Creative Commons Attribution Non Commercial 4.0 License (http://www.creativecommons.org/licenses/by-nc/4.0/) which permits nonCommercial use, reproduction and distribution of the work without further permission provided the original work is attributed as specified. 
this community is more prone to workrelated stress, however, much research is still needed to further improve the quality of care provided to patients by this community especially by improving psychological capital/ resources within the individual.

Workplace stress has been perceived as a common issue with broad impacts. National Institute for Occupational Safety and Health NIOSH (1999), defines workplace stress as when the demands and policies of the work do not match with the individual's abilities, skills, resources, and competence, then, harmful physical and psychological responses occur which is called workplace stress. Workplace stress results in poor health conditions and can even cause injury and can also affect job satisfaction. Job satisfaction refers to the "workers feeling and conception about their job". If the individual's feelings and attitude towards the job are favorable, then it is considered as job satisfaction. On the other hand, if the worker's conception and feelings toward their job are negative, then it is perceived as job dissatisfaction (Armstrong, 2006).

Literature suggests that working conditions play a critical role in maintaining job satisfaction among its employees. For example, a study by Grunfeld et al. (2005) examined work-related stress and experience of job satisfaction among workers serving in the cancer care units. The findings of the study suggested that the stressful environment at the workplace was harming the health of staff and also had a harmful outcome as far as standard of patient care services were concerned. Similarly, another study by Bahalkani et al. (2011) examined job satisfaction among nurses in different hospitals in Islamabad, Pakistan. The findings of the study indicated that the majority of the nurses $(86 \%)$ were not satisfied with their job. It was noticed that job environment, low wages, high demands, and pressure were the major factors of job dissatisfaction.

As discussed earlier, the physical and psychological load on the nursing community especially in the wake of COVID-19 may be dealt with by enhancing the personal resources within the individuals. In this regard, emotion regulation is considered an extremely important phenomenon to deal with stressful situations/circumstances. According to Gross (2014), emotion regulation is the process through which a person modifies what emotions he has, how he experiences them and when he has to express them. Emotion regulation is comprised of cognitive and behavioral processes by which an individual can alter the type and direction of his or her emotional experience (Nolen-Hoeksema, 2011). Literature review reveals that emotion regulation may act as a moderator between stress and job satisfaction. For example, a study by Hagemeister and Volmer (2018) examined social conflict and job satisfaction at workplace by assessing the role of emotional regulation as a moderator. It was found that workers with a higher level of emotion regulation abilities experienced a higher level of job satisfaction. Emotion regulation significantly moderated between workplace conflict and job satisfaction. Similarly, Too and Butterworth (2018) studied job stressors, mental health, and the moderating role of emotion regulation. The findings of the study revealed that cognitive reappraisal moderated the association between job-related stress and distress.

The literature review also suggests the role of demographics in workplace stress and job satisfaction. For example, a study by Agarwal and Sajid (2017) examined differences based on job status in job satisfaction, turnover intention and organizational commitment. Public sector employees were observed to be higher on organizational commitment and contentment 
with jobs. However, as far as the desire to quit the job is concerned, private sector employees were higher on turnover intention. A study by Sharma and Jyoti (2009) examined job satisfaction among university teachers. It was noticed that a high level of job satisfaction was associated with a higher level of occupation. It was also found that females were more satisfied than males. And married teachers were higher on job satisfaction than unmarried teachers.

There is evidence of a global shortage of nurses in both developed and underdeveloped countries (World Health Organization, 2020). According to World Health Organization (2020) statistics, the current figure of nurses in Pakistan is 0.5 per 1,000 population, however, this ratio must be 3.28 per 1,000 population. The shortage of the nursing community becomes even more critical in the recent surge of a COVID-19 pandemic. Therefore, it is important to highlight issues related to this community and to improve their resources to enhance the quality of care provided in the health sector. In this regard, the present study is an attempt to extend our knowledge regarding the relationship of workplace stress with job satisfaction specifically among the nursing population in Pakistan. Similarly, we were also interested to find out if emotion regulation moderates this relationship.

\section{Method \\ Sample and Design}

Through a cross-sectional research study, the researchers approached 120 (60 male/ 60 female) nurses through purposive sampling technique having an age range of 20-40 years. Sample of the present research comprised of nurses during COVID-19 pandemic who were working in COVID-19 wards from different government and private hospitals of Rawalpindi and Islamabad, Pakistan. Our study sample included married nurses (69) and unmarried nurses (51). Similarly, 59 nurses were from public sector hospitals whereas, 61 were from private hospitals. Trainee nurses and nurses with job experience of less than 1 year were excluded from the study.

\section{Measures}

The study variables were measured through, Workplace Stress Questionnaire (The American Institute of Stress, 2001). The scale consists of 8 items having five-point Likert scale and scored as 1(never), 2(rarely), 3(sometimes), 4(often), 5(very often). Items 6, 7, and 8 are reverse scored. Minimum score on the scale is 8 and maximum is 40 . If the respondents score 15 or lower it shows they are calm, the score ranging from 16 to 20 shows low level of workplace stress. The score between 21 to 25 shows moderate level of workplace stress, 26 to 30 is severe stress and between 31 to 40 is potentially dangerous level of workplace stress. The original Cronbach's alpha reliability coefficient is 0.70 for the entire scale.

Minnesota Satisfaction Questionnaire (MSQ)-Short form, was used to measure job satisfaction among nurses (Weiss et al., 1967). MSQ- short form has 20- items on five-point Likert scale, scored as 1(very dissatisfied), 2 (satisfied), 3 (neither satisfied nor dissatisfied), 4 (dissatisfied), 5 (very satisfied). The three components of job satisfaction or contentment measured through this scale is: General Satisfaction (G)Intrinsic Satisfaction (I), and Extrinsic Satisfaction. Minimum score on the scale is 20 and maximum was 100. The items are directly scored by totaling the value of the number choose in the relevant items. Reliability coefficient of the scale as reported by the author is 0.70 .

Emotional Regulation Questionnaire (Gross \&John, 2003) was used to assess emotional regulation. The 10 items of the emotion regulation questionnaire assess emotion regulation on two separate facets of emotions i.e. Cognitive reappraisal assessed by 6 items 
$(1,3,5,7,8,10)$ and expressive suppression assessed by 4 items $(2,4,6,9)$. Each item is scored by using 7-point rating scale (strongly agree $=7$ to strongly disagree $=1$ ). The score ranged from 6 to 42 is of cognitive reappraisal and the score range from 4 to 28 is for expressive suppression. The internal consistency for cognitive reappraisal is .79 and for expressive suppression .73.

\section{Procedure}

To gather the study data, initially, ethical approval was obtained from the research ethics committee, Psychology Department of International Islamic University Islamabad, Pakistan. Moreover, necessary permissions from the head of the hospitals were also taken. Participants of the study were ensured that the gathered information will be kept private and confidential and will only be used for study purposes. After the brief introduction of our study, informed consent was obtained from the respondents. The research instruments were then administered to120 (60 male/60 female) nurses from different hospitals of Islamabad and Rawalpindi. During data collection every confusion regarding the research instruments was made clear. Moreover, participants were requested to be honest and were acknowledged for their kind contribution.

\section{Data Analysis}

Data was analyzed by using Statistical Package for Social Sciences (SPSS) version 22. Pearson product-moment correlation and Linear regression analysis were carried out to measure the relationship of workplace stress with job satisfaction and the moderating effect of emotion regulation, respectively.

\section{Results}

\section{Table 1}

Psychometric Properties of the Variables and Scales of the Study $(N=120)$

\begin{tabular}{lccccccc} 
& & & & \multicolumn{2}{c}{ Range } & & \\
\cline { 5 - 6 } Variables & $\boldsymbol{k}$ & $\boldsymbol{\alpha}$ & $\boldsymbol{M}(\boldsymbol{S D})$ & Potential & Actual & Skew & Kurt \\
\hline TWSS & 8 & .71 & $24.00(4.12)$ & $8-40$ & $14-33$ & .18 & .12 \\
MSQ & 20 & .89 & $60.11(12.63)$ & $20-100$ & $36-81$ & -.19 & -1.11 \\
ERQ & 10 & .67 & $39.53(7.04)$ & $10-70$ & $23-51$ & -.38 & -.56 \\
CRS & 6 & .82 & $23.17(7.16)$ & $6-42$ & $11-36$ & -.11 & -1.17 \\
ESS & 4 & .71 & $16.36(4.09)$ & $4-28$ & $7-27$ & -.39 & .42 \\
\hline
\end{tabular}

Note . TWSS $=$ The Workplace Stress Scale, $\mathrm{MSQ}=$ Minnesota Satisfaction Questionnaire, ERQ= Emotion Regulation Questionnaire, CRS= Cognitive Reappraisal Subscale, ESS= Expressive Suppression Subscale

Table 1 shows psychometric properties for the major variables of the study. Values of skewness and kurtosis indicate that data was distributed normally. Alpha reliability coefficients values show that all scales and subscales have acceptable level of alpha reliability (i.e., $\alpha>.50$ ). 


\section{Table 2}

Pearson Correlation of Workplace Stress with Job Satisfaction and Turnover Intention among Nurses $(N=120)$

\begin{tabular}{clllc}
\hline Variables & $\mathbf{1}$ & $\mathbf{2}$ & $\mathbf{3}$ & $\mathbf{4}$ \\
\hline 1. Workplace Stress & --- & --- & --- & --- \\
2. Job Satisfaction & $-.82^{* *}$ & --- & --- & --- \\
3. Expressive Suppression & $.24 * *$ & $-.38^{* *}$ & --- & --- \\
4. Cognitive Reappraisal & $-.63^{* *}$ & $.80^{* *}$ & $-.81^{* *}$ & --- \\
\hline
\end{tabular}

Table 2 shows the correlation between the study variables. There is a strong negative correlation of workplace stress with job satisfaction $(r=-.82, p<.01)$ and cognitive reappraisal $\quad(r=-.63, \quad p<.01)$. Whereas, workplace stress has a significant positive relationship with expressive suppression $(r=$ $.24, p<.01)$.

\section{Table 3}

The Moderating Role of Cognitive Reappraisal and Expressive Suppression in the Relationship between Workplace Stress and Job Satisfaction $(N=120)$

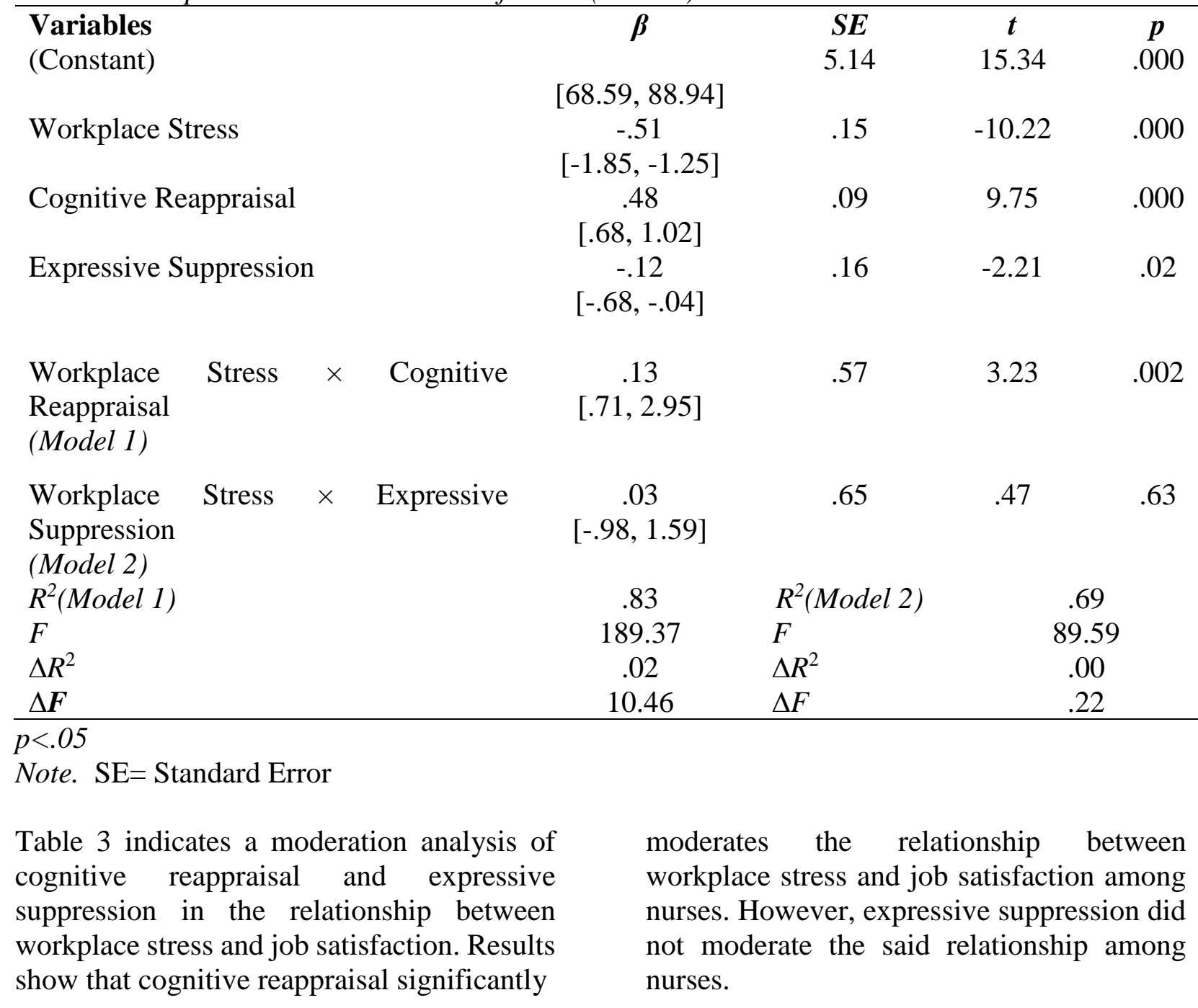




\section{Figure 1}

Moderating Role of Cognitive Reappraisal in the Relationship Between Workplace Stress and Job Satisfaction

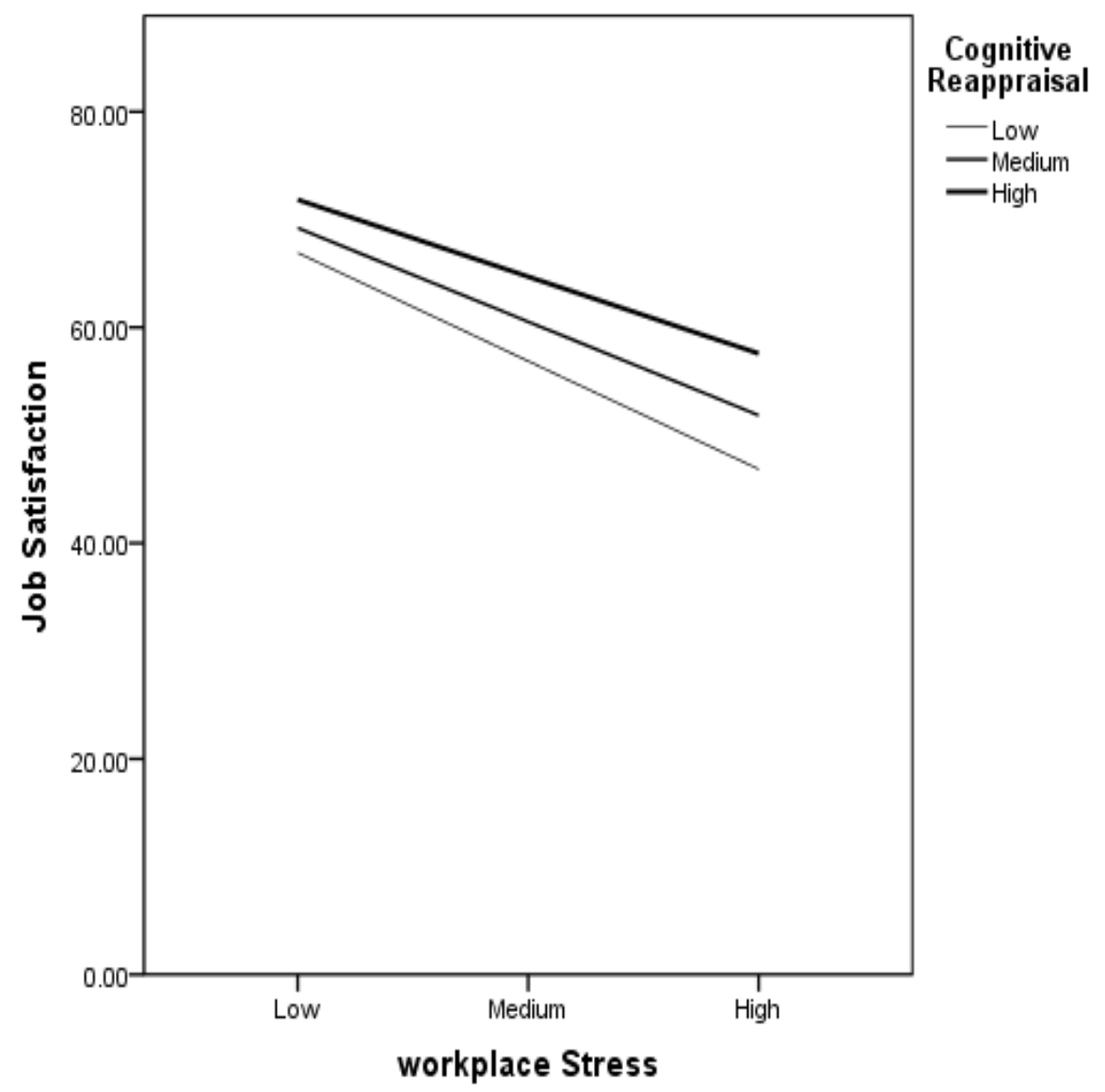

Figure 1 shows the moderating role of cognitive reappraisal between the relationship of workplace stress and job satisfaction among nurses. 
Table 4

Mean, Standard Deviations and t-values along with Gender, Marital Status and Public-Private Sector Hospitals $(N=120)$

\begin{tabular}{|c|c|c|c|c|c|c|c|}
\hline \multirow[b]{2}{*}{ Variables } & \multirow{2}{*}{$\begin{array}{c}\begin{array}{c}\text { Male } \\
(n=60)\end{array} \\
M(S D)\end{array}$} & \multirow{2}{*}{$\begin{array}{c}\text { Female } \\
(n=60)\end{array}$} & \multirow[b]{2}{*}{$t(\mathbf{1 9 8})$} & \multirow[b]{2}{*}{$p$} & \multicolumn{2}{|c|}{$95 \% C I$} & \multirow[b]{2}{*}{$\begin{array}{c}\text { Cohen's } \\
d\end{array}$} \\
\hline & & & & & $L L$ & $\boldsymbol{U L}$ & \\
\hline Workplace Stress & $21.85(6.82)$ & $24.54(7.30)$ & -2.08 & .021 & -.13 & -5.24 & .42 \\
\hline Job Satisfaction & $62.26(12.8)$ & $57.96(12.0)$ & 1.88 & .062 & -.21 & 8.81 & .34 \\
\hline Emotion Regulation & $37.48(7.89)$ & $41.58(5.41)$ & -3.31 & .001 & -1.65 & -6.55 & .60 \\
\hline Cognitive & $21.90(7.74)$ & $24.45(6.35)$ & 1.97 & .051 & -.01 & 5.11 & .36 \\
\hline \multicolumn{8}{|l|}{ Reappraisal } \\
\hline Expressive & $17.13(4.28)$ & $15.58(3.78)$ & 2.10 & .038 & .08 & 3.01 & .39 \\
\hline \multicolumn{8}{|l|}{ Suppression } \\
\hline & $\begin{array}{c}\text { Unmarried } \\
(n=51)\end{array}$ & $\begin{array}{c}\text { Married } \\
(n=69)\end{array}$ & & & \multicolumn{2}{|c|}{$95 \% C I$} & \\
\hline Variables & $M(S D)$ & $M(S D)$ & $t(\mathbf{1 9 8})$ & $p$ & $L L$ & $\boldsymbol{U L}$ & $\begin{array}{c}\text { Cohen's } \\
d\end{array}$ \\
\hline Workplace Stress & $23.11(3.85)$ & $24.65(4.26)$ & -2.05 & .042 & -3.01 & -.05 & .37 \\
\hline Job Satisfaction & $57.57(12.7)$ & $63.54(11.7)$ & -2.65 & .009 & 1.51 & 10.42 & .48 \\
\hline Emotion Regulation & $40.21(7.44)$ & $39.02(6.74)$ & .89 & .371 & -1.43 & 3.80 & .16 \\
\hline Cognitive & $24.64(7.42)$ & $22.08(6.81)$ & 1.93 & .056 & -.06 & 5.18 & .35 \\
\hline & $15.56(4.29)$ & $16.94(3.87)$ & -1.80 & .074 & -2.88 & .13 & .33 \\
\hline & $\begin{array}{c}\text { Public } \\
(n=59)\end{array}$ & $\begin{array}{c}\text { Private } \\
(n=61)\end{array}$ & & & \multicolumn{2}{|c|}{$95 \% C I$} & \\
\hline Variables & $M(S D)$ & $M(S D)$ & $t(\mathbf{1 9 8})$ & $p$ & $L L$ & $\boldsymbol{U L}$ & $\begin{array}{c}\text { Cohen's } \\
d\end{array}$ \\
\hline Workplace Stress & $23.37(4.16)$ & $24.60(4.07)$ & -1.63 & .104 & -2.72 & .25 & .29 \\
\hline Job Satisfaction & $63.01(12.0)$ & $57.32(12.6)$ & 2.51 & .012 & 1.20 & 10.14 & .46 \\
\hline Emotion Regulation & $40.54(7.03)$ & $38.56(6.97)$ & 1.55 & .123 & -.54 & 4.51 & .28 \\
\hline Cognitive & $24.08(4.28)$ & $23.91(4.04)$ & .21 & .727 & -.1 .34 & 1.67 & .04 \\
\hline $\begin{array}{l}\text { Reappraisal } \\
\text { Expressive } \\
\text { Suppression }\end{array}$ & $16.00(4.52)$ & $16.70(3.63)$ & -.93 & .350 & -2.19 & .78 & .17 \\
\hline
\end{tabular}

Note: $C I=$ Confidence Interval, $L L=$ Lower Limit, $U L=$ Upper Limit.

Table 4 demonstrates an independent sample $t$-test to investigate gender differences, marital status differences and differences based on job status in study variables. Results revealed that females were significantly higher on Workplace Stress $t(198)=-2.08$, $p<.05$, and Emotion Regulation $t(198)=-$ $3.31, p<.01$ and cognitive reappraisal $t(198)$ $=1.97, p<.05$, as compared to males.
Whereas males were significantly higher on Expressive Suppression $t(198)=2.10, p^{<}$ .05 , than females. Results further shows that married nurses were significantly higher on Workplace Stress $t(198)=-2.05, p<.05$, Job Satisfaction $t(198)=-2.65, p<.01$, as compared to unmarried nurses. Moreover, the table also shows that nurses in public sector hospitals were significantly higher on Job 
Satisfaction $t(198)=2.51, p<.05$, than nurses in private sector hospitals.

\section{Discussion}

In the recent surge of COVID-19, the health sector was affected significantly. As the nursing community constitute a major portion of the health sector, therefore, it is imperative to highlight the negative psychological outcomes faced by this community during this period and to investigate if personal resources/abilities (e.g., emotion regulation) may be used to reduce harmful effects of stress experienced by them. Having background information about this community, the current study has two main objectives: 1) to assess the relationship of workplace stress with job satisfaction among nurses working in different hospitals of public and private sector during COVID-19; 2) to investigate the moderating role of emotion regulation in the association of workplace stress with job satisfaction among the sample.

We observed that workplace stress relates negatively to job satisfaction among nurses. Indeed, the present findings indicated that nurses who experienced higher levels of workplace stress had poor levels of job satisfaction. We observed that majority of the nurses experienced high levels of stress at their workplace which lowered their levels of job satisfaction. There are sample of studies conducted worldwide as well as in Pakistan that highlight considerable impact of COVID-19 on mental health of health care workers. For example, many studies reveal mild to moderate symptoms of depression, stress and anxiety among doctors and nurses during the pandemic times (Arshad et al., 2021; Hayat et al., 2021; Shahbaz et al., 2020). Likewise, the existing literature also confirms a significant inverse relationship between job stress and job satisfaction (Ahsan et al., 2009; Brewer \& McMahaLanders, 2003; Trivellas et al., 2013).
Moreover, in the past year and a half, various studies were carried out to explore the psychological impact of COVID-19 on healthcare workers and majority have conclude that there is a dire need of initiation of psychological wellbeing programs (Arshad et al., 2021; Riaz et al, 2021). To explore the second objective, we examined the moderating role of emotion regulation in the relationship between workplace stress and job satisfaction by using moderation analysis. To have a much clear understanding of the underlying mechanisms of emotion regulation, we carried out moderation analysis separately on the subcategories of emotion regulation (i.e. Cognitive reappraisal and expressive suppression). It was noticed that only cognitive reappraisal positively moderated the relationship between workplace stress and job satisfaction among nurses. The study findings highlighted that with the effective use of cognitive reappraisal strategies, the negative effects of workplace stress were buffered. A possible explanation for such findings is that in contrast to expressive suppression, cognitive reappraisal is a strategy that helps to reframe the emotional situation before the behavioral response so, nurses in the present study who reported high cognitive reappraisal, experienced less workplace stress and more job satisfaction. It is also evident from the literature that cognitive reappraisal has a positive impact by decreasing unhealthy emotions as compared to expressive suppression (Gross, 2014). However, expressive suppression did not moderate the said relationship among the present sample. These findings are also supported by the previous research by Zahniser (2016), which highlight the significance of emotion regulation, specifically cognitive reappraisal as a barrier against stress. 
Findings further suggested significant differences based on demographic variables like gender, marital status and job status, in workplace stress and job satisfaction and emotion regulation strategies among nurses. We found significant differences in workplace stress and emotion regulation based on gender. It was found in the current study that female nurses were significantly higher on workplace stress. This difference may also be justified with the known fact that women are having multiple responsibilities toward their home as compared to men which may be a significant determinant of higher workplace stress. The present findings are consistent with studies conducted in this regard, for example, Shahbaz et al (2021) demonstrate that female health care workers are more vulnerable and psychosocially challenged as compared to men. They further added various factors contributing towards this vulnerability. These findings are parallel to previous studies, for example, Yada et al. (2014) revealed that female nurses had higher stress levels than male nurses. However, an important finding of the current study that requires to be highlighted is that female nurses were high on cognitive reappraisal than males. The higher levels of cognitive reappraisal among the female sample may be attributed to the fact that women are more emotional and ruminate more frequently than men. Various studies from the literature review confirm these findings (e.g., NolenHoeksema \& Aldao, 2011). Results of the current study, however, reported that male nurses used more expressive suppression strategies than female nurses. We attribute this difference to the fact that women, while usually expressing their emotions openly; men think that expressing their emotions is less than manly. These findings are parallel to the previous research findings i.e., men were more likely to engage in expressive suppression than did women (Zahniser, 2016).
Similarly, another significant finding was that married nurses were higher on workplace stress. As the data was collected in the COVID-19 pandemic so most married nurses were experiencing mental exhaustion as they had to self-isolate themselves from the family for possibly transmitting illness, even after working hours. Consequently, this isolation has a great impact on reducing their job satisfaction levels and increasing workplace stress among the married sample as it was prohibiting them from fulfilling responsibilities at home. These differences were also consistent with the previous findings which suggest that married women experienced high levels of job stress than unmarried women (Parveen, 2016).

In the current study, we also aspired to see differences based on job status (public\& private sector). In this regard, we observed that public sector nurses were higher on job satisfaction as compared to private sector nurses. These differences may exist because in Pakistan, jobs in the public sector offer more job incentives and job security than the private sector. Previous research work, however, revealed mixed results. For instance, Waqar and Hamid (2016) examined that working conditions and working relations were considered as more satisfying among private hospital nurses. However, as far as duty hours, benefits pay, and other incentives were considered, the public sector nurses were more satisfied. In another study, public sector employees were observed to be higher on job satisfaction.

\section{Conclusion}

Nursing has always been a demanding and stressful job however, in the special circumstances of COVID-19, it has become a quite serious concern for the health authorities. The findings of the present study conclude that workplace stress as a common negative outcome for healthcare workers especially during the COVID-19 environment may be reduced by teaching 
them to use their own emotion regulating abilities. The hospital administrations should conduct frequent workshops to train the nursing population for using their psychological resource of emotion regulation for better mental health. It might have a positive effect not only on their job satisfaction levels but also may reduce their turnover intention.

\section{Conflict of Interest}

The authors declare no conflict of interest.

\section{Source of Funding}

The authors declare no funding.

\section{References}

Agarwal, P., \& Sajid, S. M. (2017). A study of job satisfaction, organizational commitment, and turnover intention among public and private sector employees. Journal of Management Research, 17(3), 123-136.

Ahsan, N., Abdullah, Z., Fie, D. Y. G., \&Alam, S. S. (2009). A study of job stress on job satisfaction among university staff in Malaysia: Empirical study. European Journal of Social Sciences, 8(1), 121-131.

Armstrong, M. (2006). A handbook of human resource management practice. Kogan Page Publishers.

Arshad, M.S., Hussain, I., Nafees, M., Majeed, A., Imran, I., Saeed, H., Hashmi, F.K, Akbar, M., Abrar, M.A., Ramzan, B., Chaudhry, M.O., Islam, M., Usman, A., Nisar, N., \& Rasool, MF. (2021). Assessing the Impact of COVID-19 on the Mental Health of Healthcare Workers in Three Metropolitan Cities of Pakistan. Psychology Research and Behavior Management, 13, 1047-1055. https://doi.org/10.2147/PRBM.S282069

Bahalkani, H. A., Kumar, R., Lakho, A. R., Mahar, B., Mazhar, S. B., \& Majeed, A. (2011). Job satisfaction in nurses working in tertiary level health care settings of
Islamabad, Pakistan. Journal of Ayub Medical College Abbottabad, 23(3), 130133.

http://www.ayubmed.edu.pk/JAMC/233/Bahalkani.pdf

Brewer, E., \&McMaha-Landers, J. (2003). The Relationship Between Job Stress and Job Satisfaction of Industrial and Technical Teacher Educators. Journal of Career and Technical Education, 20(1).http://dx.doi.org/10.2 1061/jcte.v20i1.622

Drennan, V. M. (2019). More care out of hospital? A qualitative exploration of the factors influencing the development of the district nursing workforce in England. Journal of health services research \& policy, 24(1), 11-18.doi: 10.1177/1355819618769082

Gross, J. J. (2014). Emotion regulation: Conceptual and empirical foundations. In J. J. Gross (Ed.), Handbook of emotion regulation (pp. 3-20). The Guilford Press.

Gross, J. J., \& John, O. P. (2003). Individual differences in two emotion regulation processes: implications for affect, relationships, and well-being. Journal of Personality and Social Psychology, 85(2), 348.doi: 10.1037/0022-3514.85.2.348.

Grunfeld, E., Zitzelsberger, L., Coristine, M., Whelan, T. J., Aspelund, F., \& Evans, W. K. (2005). Job stress and job satisfaction of cancer care workers. PsychoOncology: Journal of the Psychological, Social and Behavioral Dimensions of Cancer, 14(1), 61-69.doi: 10.1002/pon.820.

Hagemeister, A., \& Volmer, J. (2018). Do social conflicts at work affect employees' job satisfaction? The moderating role of emotion regulation. International Journal of Conflict Management, 29(2), 213-235. 
http://dx.doi.org/10.1108/IJCMA-112016-0097

Hayat, K., Arshed, M., Fiaz, I., Afreen, U., Khan, F.U., Khan, T.A., Kadirhaz, M., Shukar, S., Saeed, A., Gill, M.R., and Fang, Y. (2021). Impact of COVID-19 on the Mental Health of Healthcare Workers: A Cross-Sectional Study From Pakistan. Frontiers in Public Health, 9, 603602. doi: 10.3389/fpubh.2021.603602

National Institute for Occupational Safety and Health (NIOSH) (1999). Stress at Work. Centers for Disease Control and Prevention, U. S. Department of Health and Human Services. Publication no. 99101.

Nolen-Hoeksema, S., \&Aldao, A. (2011). Gender and age differences in emotion regulation strategies and their relationship to depressive symptoms. Personality and individual differences, 51(6), 704708.DOI:10.1016/j.paid.2011.06.012

Parveen, S. (2016). Acute shortage of nursing professional in Pakistan. Texila International Journal of Nursing, 2, 1-6. DOI:10.21522/TIJNR.2015.02.01.ART 020

Riaz, B., Rafai, W.A., Ussaid, A., Masood, A., Anwar,S., Baig,F.A., Saleem, K., Nasir, S.A., $\quad$ Firdous, Z., \& Iqbal, F. (2021). The Psychological impact of covid-19 on healthcare workers in Pakistan. Future Health Care Journal. 8(2), e293e298. doi: 10.7861/fhj.2020-0193

Shahbaz, S., Ashraf, M.Z., Zakar, R., Fischer, F. (2021). Psychosocial, emotional and professional challenges faced by female healthcare professionals during the COVID-19 outbreak in Lahore, Pakistan: a qualitative study. $B M C$ Women's Health, 21, 197. https://doi.org/10.1186/s12905-02101344-y
Sharma, R. D., \& Jyoti, J. (2009). Job satisfaction of university teachers: an empirical study. Journal of Services Research, 9(2), 51-80.

The American Institute of Stress (2001). Workplace Stress Scale (WSS). The Marlin Company, North Haven, Connecticut and, Yonkers, New York.

Too, S. L., \& Butterworth, P. (2018). Psychosocial job stressors and mental health: The potential moderating role of emotion regulation. Journal of Occupational and Environmental Medicine, 60(10) ,e518-e524. DOI:10.1097/JOM.0000000000001416

Trivellas, P., Reklitis, P., \&Platis, C. (2013). The effect of job-related stress on employees' satisfaction: A survey in health care. Procedia-Social and Behavioral Sciences, 73, 718726.DOI:10.1016/j.sbspro.2013.02.11 0

Waqar, S., \& Hamid, S. (2016). Job satisfaction among nurses in public and private hospitals of Rawalpindi and Islamabad. Pakistan Journal of Public Health, 6(4), 4448.DOI: 10.2147/JMDH.S55077

Weiss, D.J Davis, R.V, England, G.W and Lofquist, L. H. (1967). Manual for the Minnesota Satisfaction Questionnaire. Minnesota: IRC. University of Minnesota.

World Health Organization (April 7, 2020). WHO and partners call for urgent investment in nurses. https://www.who.int/news/item/07-042020-who-and-partners-call-forurgent-investment-in-nurses

Yada, H., Abe, H., Omori, H., Matsuo, H., Masaki, O., Ishida, Y., \&Katoh, T. (2014). Differences in job stress experienced by female and male Japanese psychiatric nurses. International Journal of Mental 
Health Nursing, 23(5), 468476.DOI: 10.1111/inm.12080

Younas, A., Rasheed, S. P., \& Sommer, J. (2019). Current situation and challenges concerning nursing education in Pakistan. Nurse education in practice, 41, 102638. https://doi.org/10.1016/j.nepr.2019.102 638
Zahniser, E. (2016). The Moderating Role of Emotion Regulation on Longitudinal Associations between Stress and Mental Health in College Students. Master Thesis. 3158. https://ecommons.luc.edu/luc_theses/3 158 